Review

\title{
Working with human nature to achieve sustainability: Exploring constraints and opportunities
}

\author{
Helen Kopnina \\ Institute Cultural Anthropology and Development Sociology, Faculty Social and Behavioural Sciences, Leiden University, Wassenaarseweg 52, 2300 RB, \\ Leiden, The Netherlands
}

\section{A R T I C L E I N F O}

\section{Article history:}

Received 24 July 2016

Received in revised form

13 January 2017

Accepted 8 February 2017

Available online 9 February 2017

\section{Keywords:}

Cradle to cradle

Human nature

Sustainable production

Sustainability

Universals

\begin{abstract}
A B S T R A C T
Sustainable production is often limited by structural factors such as industrial development, neoliberal democracy, growing population and globalization of consumer culture. Drawing on the work of some theorists linking unsustainability to universal psychological propensities, this article discusses sustainable production in relation to human nature. Human nature is understood here as complex cross-cultural and historically consistent psychological traits or universal physiological predispositions that result in the largely shared repertoire of human behavior. It is posited here that these traits, when combined with specific conditions of industrial development result in unsustainable behaviors. This article explores the relationship between human population and sustainability, human nature and culture as well as human nature and environment, and between human nature and sustainability. Recommendations focus on how sustainability efforts can take advantage of some of our natural tendencies, and mitigate others in order to provide strategic solutions to unsustainable practices.
\end{abstract}

(C) 2017 Elsevier Ltd. All rights reserved.

\section{Contents}

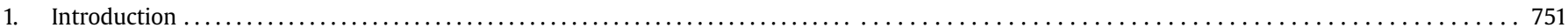

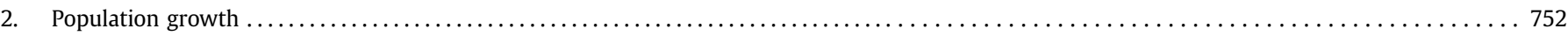

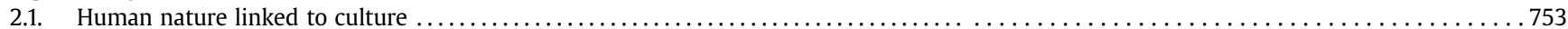

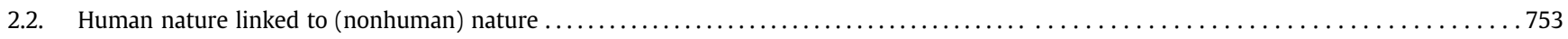

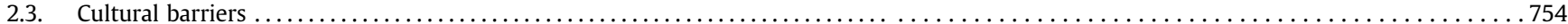

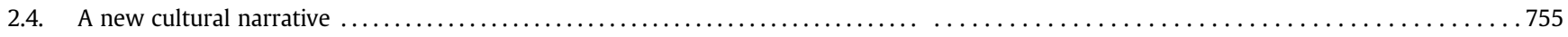

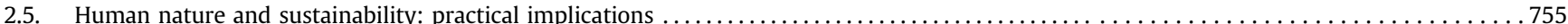

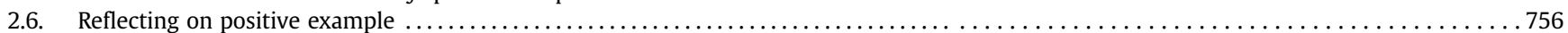

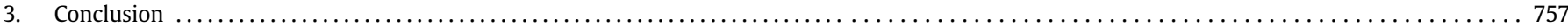

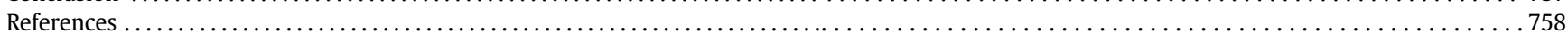

\section{Introduction}

Human nature has had a status of the grand old theory for the duration of our intellectual history, falling in and out of favor as an explanatory concept of human behavior within various disciplines. Human nature has been defined as a set of psychological and physiological predispositions or universal propensities arising from

E-mail addresses: h.kopnina@hhs.nl, h.n.kopnina@fsw.leidenuniv.nl. a number of cross-culturally shared characteristics (e.g. Wilson, 1993; Fukuyama, 1999; Kaplan, 2000; Rees, 2010; Pinker, 2011). American anthropologist Donald Brown (1991) refers to human nature as a collection of 'universals', exemplifying them by the types of realms in which these occur. To name just a few, "those in the cultural realm include myths, legends, body adornment, daily routines, rules, concepts of luck and precedent, and the use and production of tools; in language there are grammar, phonemes, polysemy, metonymy, antonyms, and an inverse ratio between the frequency of use and the length of words; in the social realm there 
are a division of labor, social groups, age grading, the family, kinship systems, ethnocentrism, play, exchange, cooperation, and reciprocity; in the behavioral realm there are aggression, gestures, gossip, and facial expressions; mentally there are emotions, dichotomous thinking, empathy, and psychological defense mechanisms" (Ibid p. 118).

The originator of the 'ecological footprint' concept William Rees (2010) relates consistent features of human nature to the issues of (un)sustainability. In the article titled What's blocking sustainability, Rees (2010) puts forth a theory that modern humans are unsustainable by nature, connecting human nature to certain evolutionary traits, such as subconscious, genetic predisposition to expand (shared with all other species), both territorially and in numbers. Rees argues that this propensity to expand become maladaptive when strengthened by industrial development, neoliberal democracy, growing population and globalization of consumer culture. The capitalist market system typically demands the "externalization of social and environmental costs, an economic system wedded to continuous growth, a hierarchical social system that scripts for consumption as a means of both inclusion and exclusion; and a political system unable or unwilling to regulate consumption for fear that doing so would threaten the tax base" (Isenhour, 2015a, 2015b:146).

Sustainability-related universals include, but are not limited to, the propensity for technological innovation, the desire to elevate one's status through material possession and preoccupation with social justice (Kopnina, 2013a). Technological innovation might have unintended side effects, such as efforts to address climate change through geo-engineering, which often entail unacceptable levels of risk as these techniques would have to be continued for the indefinite future, for failure to do so would lead to a potentially catastrophic surge in greenhouse gases (Nemetz, 2015). Material markers of status lead to consumption of unsustainable products, such as cars. Social justice leads to the promotion of equitable economic growth (e.g. United Nations, 2015), that resulting in globalization of unsustainable practices (Hansen and Wethal, 2014).

Sustainability in this article will refer to issues associated with depletion of natural resources, pollution, climate change, and biodiversity loss. This article will distinguish between conventional (or mainstream) and transformative (or radical) approaches to sustainability (Kopnina and Blewitt, 2014). Unsustainable production is characterized by the 'cradle to grave' system in which materials are extracted, used and wasted (McDonough and Braungart, 2002). Conventional approaches to sustainability attempt to reduce damage through the triple $\mathrm{R}$ ('reduce reuse, and recycle'), or ecoefficiency (Blowfield, 2013). The more transformative approaches, including Cradle to Cradle (C2C) and circular economy, focus on a radical re-evaluation of production strategies that eliminate damage altogether (McDonough and Braungart, 2002; Bocken et al., 2014; Kopnina, 2016; Lieder and Rashid, 2016; Witjes and Lozano, 2016).

Transformative approach to sustainability requires the design of policies that specifically take advantage of some of our natural tendencies, and mitigate others (Fehr-Duda and Fehr, 2016). While natural characteristics can be harder to counter, human beings are also products of their culture (Ingold, 2006). Most human behaviors are both learned and natural (Wilson, 1984). Capacity for empathy, for example, can be 'natural', at least in some people, but it can also be nurtured. Thus altruism can be seen as both 'inborn' and learned. Self-interest is essential to all species' survival, but can be also conditioned by 'merchant values' of capitalist industrial societies.

This article will examine whether both self-interest and altruism can be balanced in such a way that sustainable choices become more 'natural'. The relevance of the concept of human nature to understanding (un)sustainability will be explored in sections on the relationship between human population and sustainability, human nature and culture, between human nature and Nature (environment), and finally, between human nature and sustainability. The concluding section will outline possible strategic solutions in addressing unsustainable practices by examining both inherited predispositions and learned attitudes and behaviors. This article will culminate in suggestions as to what altruism/selfinterest or competitive/cooperative behavior can be taken advantage of, and how to mitigate others.

\section{Population growth}

Population growth is one of the most pressing and yet least dealt with sustainability challenges that can be discussed along the "altruism/self-interest lines". While critical authors have noted that population growth is a single most important source of continuing crises of natural resources (e.g. Rees, 2010; Washington, 2015; Daly, 2016), others consider it to be positive (Simon, 1981; Goklany, 2007; Fletcher et al., 2014). Simon (1981) or Goklany (2007) have stated that the population growth is an essential prerequisite for the development of more efficient and cleaner economies. From a neoliberal economics point of view, population growth is celebrated since greater population implies greater economic growth and expanding markets (Blowfield, 2013). Basically, the more people, the more consumers, the larger the labor force, the more young people to pay old people's pensions. For this reason, in many countries high fertility is actually stimulated (see, for example, population-related issues of The Economist, 2012a; 2012b).

It has been argued that having more children in poor countries can ensure greater survival rates and provide the parents with additional sources of income from working children (Blowfield, 2013). Some scholars have argued that since most population growth happens in the poorest countries of sub-Saharan Africa, those that want to limit population growth do not take the needs of the poor into account (Fletcher et al., 2014). Since most poor people's carbon footprint is negligible, it is argued that population growth serves as a scape-goat for sustainability discourse that distracts from the necessity to address economic growth in industrially developed countries (Ibid). Partly due to these altruistic concerns, and partly due to a number of social and political sensitivities, linking population growth to sustainability has become a taboo (Washington, 2015).

While economic growth in industrial countries is certainly a major contributor to unsustainability, critical scholars have noted that the question of population growth cannot be ignored. Western donors might be truly altruistic in promoting worldwide vaccination and hygiene programs. Yet, the self-interest in being able to live decent lives and to provide for future generations also needs to be considered.

Wijkman and Rockström (2012) and Washington (2015) have argued that a position that population is 'not a problem' actually ignores the needs of the poor themselve. First, a high birth rate exacerbates poverty (United Nations, 2015). Second, higher fertility is often associated with failures to address human rights and women's rights (Wijkman and Rockström, 2012). Memory Banda, a Malawian girl who told her story on TED talk clearly indicates the extent of the problem of unwanted pregnancies due to rape and child marriage (Banda, 2015). By some estimates, there are about 215 million women who want access to contraception but are denied it (Campbell, 2012; Hindin et al., 2016). Consequently, in the many parts of the world the number of women of child-bearing age is disproportionately large, this 'population momentum' being likely to outrun fertility decline (e.g. Singh et al., 2010).

Also, the perspective that the poor's carbon footprint is negligible and thus unrelated to sustainability concerns is very short- 
sited (Wijkman and Rockström, 2012). From the perspective of social justice one cannot expect that the poor will never escape poverty, nor ever migrate to the more economically developed countries (Kopnina and Washington, 2016). Additionally, while concerned about social fairness, proponents of population growth Simon (1981) or Goklany (2007) do not consider planetary fairness. As Crist (2012) has sarcastically remarked:

As Julian Simon (1981) rightly pointed out, with much anthropocentric pomposity, resources are highly malleable. Consider the ways. The resource base can be enlarged: for example, more land under the plough, more groundwater discovered, more oil and mineral reserves found, etc. The services of previously depleted or forsaken resources can be accessed through new or alternative ones: for example, biofuels, tar sands, wind energy, electric cars, artificial meat, hydroponics, etc. Resource-use efficiency can be intensified or revolutionized: for example, by eliminating food waste, dematerialization, recycling industries, etc. ... As long as such a "resource enhancement portfolio" can be developed and implemented, then an increasing and eventually very large stable population might be supportable; maybe such a large population can even be provided with a highconsumption way of life. Environmentalists' objection to this Simonian reverie, of billions of people enjoying a global consumer culture and expanding the human empire to the universe at large, is that limitlessly enhancing the resource base eventually results in breaching biophysical limits, with consequences like climate change, agricultural and industrial pollution, peak oil, and the severe degradation or loss of ecological services ... More serious than modern society's potential ability to technologically fix or muddle through problems of its own making is people's apparent willingness to live in an ecologically devastated world and to tolerate dead zones, endocrine disruptors, domestic animal torture (aka CAFOS), and unnatural weather as unavoidable concomitants of modern living.

While all people want to live decent lives, there is a large debate about whether having many children is a natural tendency or whether it is simply caused by unavailability of birth control (Campbell, 2012; Crist, 2012; WHO, 2016). 'Naturally', it can be argued, humans exhibit expansionist tendencies, and like all other species, maximize their comparative advantage (Rees, 2010). Due to antibiotics, vaccines and other medical advances, and the absence of political initiatives such as the recently abandoned one-child policy in China, as well as relative peace, one would suppose that it is 'natural' to produce more children that survive to adulthood. However, some countries show that despite availability of contraception (freely distributed by development agencies) and education (without specifying the level of educational achievement) female fertility has not subsided (Wijkman and Rockström, 2012). The fact that wealthier and more educated societies have chosen to have less children (Campbell, 2012), also speaks of differential cultural adaptation.

Unless one assumes that persistent high fertility rates in SubSaharan Africa are due to 'natural' factors, greater accent on cultural mechanisms favouring large families need to be sought. Cultural factors such as the prestige associated with having larger families and persistent belief that having more children can help families economically also need to be addressed (Wijkman and Rockström, 2012; Engelman, 2013; WHO, 2016).

\subsection{Human nature linked to culture}

Cognitive psychologists have noted that values are not 'innate' but conditioned by cultural and social conventions. While successful commercial marketing has helped to stimulate consumption, there are also other emotional, social, and cultural factors that play a role (Isenhour, 2015a, 2015b). In anthropology, the focus is most frequently on the cross-cultural differences in shaping knowledge about and behavior toward nature and specific local conditions that influence value orientations (Ingold, 2006). These value orientations include environmentalism, which has been linked to religions that render the environment as sacred (e.g. Sponsel, 2016), or predisposing adherents to devalue the environment (e.g. Taylor, 2010). Aside from religion, conservation psychologists have provided support to the hypothesis that early childhood exposure, including playing in trees or with animals, hiking, camping, fishing, and mushroom picking, enhance person's identification with nature (Sivek, 2002; Chawla and Cushing, 2007). These experiences are supposed to form key 'entry-level variables' that predispose people to take environmental action (Chawla and Cushing, 2007).

Yet, this research is contested. Studies linking exposure to nature to positive environmental attitudes do not explain why some people who grew up next to forest areas, for example, have not protested against logging, while others from the same villages, or from cities, did (e.g. Kopnina, 2015a). Indeed, love of forests might be 'innate' in some people (Wilson, 1984; Kellert and Wilson, 1995), while conditioned in others, with other priorities (such as profit from logging) coming into play. By contrast to the particularistic approaches that single out culture, religion, or experience in shaping environmental values, interdisciplinary work spanning the fields of evolutionary science (e.g. Panksepp, 1998), environmental sociology (e.g. Dunlap and Van Liere, 1978), cognitive and physical anthropology (e.g. Konner, 2003), and cognitive psychology (e.g. Schwartz, 1994), has focused on universals that underlie human thought, or common behavior patterns rather than cultural outliers (Kirner, 2017).

\subsection{Human nature linked to (nonhuman) nature}

Humans, like all animals, have adapted to the natural environments for millennia. Environmental determinism theory has postulated that natural surroundings were conducive, but also limiting, of the development of diverse cultures across the globe (Ratzel, 1896). While more contemporary theories dispute this determinism, the fact that social elements were associated with the material culture is largely undisputed as the materials people use to build their houses from, and the food they eat, were made from what is available to them (e.g. Benyus, 1997). Obviously, the situation of building from local materials and eating locally grown crops is very different in the world of cross-national supply chains and global production networks. Yet, according to E.O. Wilson (1993) "It would ... be quite extraordinary to find that all learning rules related to that world have been erased in a few thousand years, even in the tiny minority of peoples who have existed for more than one or two generations in wholly urban environments." Simply put, humans (still) need nature, and the notion of sustainability addresses this basic need (Lewis, 1996; Polasky et al., 2012; Washington, 2015). If human (as well as nonhuman) lives are to be achieved the balance between human nature and Nature as a whole needs to be found. One of the key motivators can be selfinterest in realizing that Nature supports us as species.

Yet, this pragmatic realization of self-interest and utilitarian approach to nature preservation alone is not enough. Despite the fact that some individuals care about environment or individual species, there is a growing proportional difference between the number of people and the number of nonhumans, other than those used in food production and medical experimentation industries. While small fragmented habitats can sustain smaller species, 
accommodating larger animals, and securing the stability and integrity of the entire ecosystem, requires a larger territory (e.g. Noss, 1992). While the apex predators are normally checked by environmental constraints, this is no longer the case for our own species (Shoreman-Ouimet and Kopnina, 2016).

As Vucetich and Nelson (2013) have noted, the practical import of acknowledging nature's intrinsic value rises from the recognition that some elements of nature, including endangered species, offer little direct benefit to human welfare. Contrary to the evidence about high interdependency of all species (e.g. Polasky et al., 2012), it appears that humans are well-supported by monocultures (Crist, 2012). Thus, we need to learn to care for the entire planetary community that includes nonhumans, an aim that is encompassed in the notion of altruism.

Combinations of propensities such as the ability to empathize with others, but also the ability to follow one's own self-interest, are at times mutually exclusive, but at times complementary. For example, expanding the benefits of globally spread distribution of cheap products creates new labor markets and new groups of consumers, which further enrich the established corporate and political elites (Washington, 2015). The propensity to acquire wealth (which can be seen as selfish) but also to share the benefits of natural resource exploitation globally (which can be seen as a moral virtue) leads to the perpetuation of unsustainable production. While development aid agencies and humanitarian nongovernmental organizations (NGO's) seek public support by appealing to the altruistic side of their donors, the more profitoriented organizations, such as the World Bank, might be motivated by the lucrative benefits of global economic development (Hansen and Wethal, 2014).

On the one hand, as poorer people may not be able to afford the more expensive fair trade, organic, or animal welfare-conscious food, the social altruism would support availability of less 'responsible' cheaper products. However, there is also evidence that poor people actually care more about animal welfare and thus buy animal-friendly products because they experience more vulnerability, which may make it easier to empathize with other downtrodden groups (Deemer, 2015).

There are a number of natural tendencies that are conductive to this aim. One such tendency is the universal evidence of biophilia, or love of nature (e.g. Wilson, 1984; Kopnina, 2015a). Wilson (1984) hypothesized the "innately emotional affiliation of human beings to other living organisms" explains environmentalist action by individuals as cross-cultural, despite severe repercussions, demonstrating that commitment to environmental causes, however diverse, is a universal phenomenon (e.g. Kellert and Wilson, 1995; Kopnina, 2015a). Collective biophilia can be helped by education that fosters a sense of responsibility to nonhumans, the way education has helped to foster humanitarian values in the past (Kopnina and Gjerris, 2015).

\subsection{Cultural barriers}

Chawla and Cushing (2007) have noted that students with greater knowledge about the environment or more proenvironmental attitudes are more likely to report action for the environment, but only when other structural barriers area addressed. Despite realization of our dependency on environment, there is a large gap between rhetoric of sustainability and sustainable behavior (Kollmuss and Agyeman, 2002), or the so-called knowledge-behavior gap, with prohibitions of environmentally unfriendly behaviors having little effect. Despite availability of correct information, human beings sometimes fail to behave rationally due to a number of evolutionary, psychological, and adaptive predispositions (e.g. Kaplan, 2000; Rees, 2010; Kopnina, 2013a).

Consider this simple example. At my educational institution, there are paper recycling bins placed next to the general garbage bins. Both types of bins are located close to the printing/copying machines. Often times, papers are deposited in general bins, and plastic cups and other objects are stuffed through the narrow slots of the paper recycling bins. Without financial incentives or punitive measures, reliance on individual responsibility or behavior change can be insufficient for sustainable action. It is questionable whether well-informed and well-intentioned behavior of those that separate garbage is significant in the face of majority patterns of behavior.

While we can hardly say that a mundane habit of garbage disposal is part of human nature, it is clear that relying on individual's sense of responsibility can lead to tons of paper being wasted daily. Without financial rewards or punitive incentives, some individuals (e.g. other than the responsible few who are by choice vegetarian, or do not use cars or smart phones, etc.), will choose the easy, cheap and essentially unsustainable option. Thus, while incentives can be different - appeal to altruistic values or to self-interest through financial rewards or punishments - it is the necessity to appeal to the majority of product users. Yet, the most effective means of addressing this irresponsible behavior is not offering the choice of acting unsustainably - the so-called consumer-choice editing (Blowfield, 2013), or the system in which products produced not have to be wasted - a point discussed in the section below.

A larger example of knowledge-behavior gap involves that of climate change. For all the torrent of scientific reports and the robust evidence gathered by the Intergovernmental Panel for Climate Change (IPCC), according to the analysis of internet searches, climate change commands a good deal less public attention than Kim Kardashian, a reality-TV star (The Economist, 2015a). While structural factors such as climate-averse policies that favor fossil-fuel energy are part of the answer, psychological barriers also impede behavioral choices that would facilitate mitigation, adaptation, and environmental sustainability (Gifford, 2011). Gifford (2011) notes that although many individuals are engaged in some ameliorative action to address climate change they are hindered by psychological barriers. These include limited cognition, ideological world views that tend to preclude proenvironmental attitudes and behavior, comparisons with key other people, sunk costs and behavioral momentum, mistrust toward experts and authorities, perceived risks of change, and positive but inadequate behavior change.

Obviously, these adaptive predispositions are not solely determining our behaviors. There are large cultural differences between how people make objects, what the objects mean and how they are consumed (Wilk, 2011). There are, for example, many 'sustainable communities' known in anthropological record (e.g. Sponsel, 2016), including indigenous societies and urban environmentally aware minorities. However, since the aim of sustainability is to move the majority, not just the committed fringe, toward less environmentally destructive practices (Miller, 2001), more regulative approaches are needed.

Yet, democratic governments might not be as successful in regulating as they are subject to public pressures as well as influences of (industrial) lobbies (e.g. Washington, 2015). The Economist (2012b) observes that people's beliefs are determined by feelings of cultural and political identification. When asked for their views on climate change, American Republican or Democratic voters translate this into a question of whose side are you on (The Economist, 2015a). This apparently irrational, emotional, and culturally determined response, can be attributed to universal human desire for group belonging (Isenhour, 2015a, 2015b) and the 
perceived need to conform to social status expectations (Kollmuss and Agyeman, 2002). Here again we see how cultural and social norms may be reinforced by natural tendency for group belonging, or for developing certain routines - all patterns also observed in other mammalian species (Panksepp, 1998).

Another tendency that might explain today's unsustainability is the inherent acquisitiveness of all human beings, as well as universal belief in linking possessions to their social status (in Wilk, 2011). However, "conspicuous consumption" (Veblin, 1902) may also be reflective of a need generated within a particular historic context and mode of production and not an innate trait. The present-day urge to overconsume is probably a learned or culturally mediated trait, perpetuated by industrocentric ideology of economic growth and open markets (e.g. Ingold, 2006; Wilk, 2011; Kidner, 2014). An anthropologist has Clifford Geertz stated "There is no such thing as a human nature independent of culture" (1973:49). Indeed, what we might be talking about in the case of inability to deal with the threat of climate change is overconfidence in the face of threat of suffering consequences of climate change and a common culture of denial (Rees, 2010; Washington, 2015). This denial can also be seen as a 'natural' mechanism of escaping the necessity to make difficult adjustments, such as the necessity for a politician to prohibit the use of subsidies for fossil fuel lobbies, or the necessity of a consumer to give up his/her oil-guzzling car or methane-generating meat diet (e.g. Ayres et al., 2013).

The Economist (2015b) recommends that action on climate change should be more concerned about adaptation rather than mitigation to climate change. According to this article, humanity will 'have to adapt, in part by growing crops that can tolerate heat and extreme weather, in part by abandoning the worst-affected places'. As for biodiversity, The Economist (2015b) suggests, 'Animals and plants will need help, including transporting them across national and even continental boundaries. More research is required on deliberately engineering the Earth's atmosphere in order to cool the planet'. Such a recommendation suggests that the dire predicament the planet can be remedied by the same very mechanism that has created this predicament in the first place the belief in human ingenuity and technical ability to solve the problems of its own making (Rees, 2010; Kopnina, 2013a). This belief is not necessarily part of human nature but an outgrowth of the Western Social Paradigm (Dunlap and Van Liere, 1978)), or industrocentric ideology (Kidner, 2014). This ideology is based on the belief that humans are superior to nature and in control of science and technology. Prosperity results from the exploitation of natural resources (presupposing their continuous abundance), achieved through economic growth. Since this is a dominant paradigm in most modern societies, the 'culture of majority' is created in which the arrogance of humanity is universally accepted (Ehrenfeld, 1978). This universal acceptance is manifested by the eagerness of developed countries to emanate the developed countries' 'progress'. On the global scale, the noble aim of equitable redistribution of limited resources stimulating the 'catch-up' with the rich countries does not bode well for the planet (Hansen and Wethal, 2014). As illustrated by The Economist's (2015b) opinion that in our 'bold thinking' about relocating entire populations both human and nonhuman -we need to address that dominant culture that threatens to endanger life on this planet.

\subsection{A new cultural narrative}

Post-humanist education, for example, questions the ontological and epistemological assumptions underlying notions of human nature, and draws attention to the myriad ways in which animals are always already part of ourselves, our learning, and our culture (Spannring, 2016). In doing so, education about animals, plants, or entire 'nature' combines knowledge with effective and ethical appeals targeted at enhancing pro-environmental attitudes. Critique of industrocentric ideology (Kidner, 2014) needs to be specifically tackled in education (Kopnina, 2012).

Rees (2010) notes that the world community must write a new cultural narrative that is explicitly designed for living on a planet of limited resources, a 'narrative that overrides humanity's outdated innate expansionist tendencies' (P. 13). Rees (2010) suggests that cultural conditioning should actually override natural tendencies, addressing structural constraints created by industrocentric modern culture that exacerbates human natural tendency for expansion. Culture and nature here are seen as intertwined, mutually reinforcing, but also, simultaneously, able to check one another. Indeed, human nature always acts in accord with historical, social and cultural conditions (Kopnina, 2013a). Unsustainability inevitably emerges out of the systemic interaction between universal propensities, as well as specific features of contemporary technoindustrial society and the ecosphere (Rees, 2010). The natural tendency to expand, for example, is currently reinforced by the socially constructed economic narrative of the desirability of continuous economic growth and the need to control nature (Rees, 2010). Yet, this need to control nature is also learned, and not 'inherited' and can thus be easily unlearned through alternative narrative.

Yet, those who try to explain global unsustainability by structural factors alone do not necessarily address the underlying mechanisms that enable these conditions to emerge and dominate in the first place. Complementary to recognizing industrocentric ideology, evolutionary, cognitive, and motivational approaches to human behavior have been revealing in how people create and relate to environmental problems (Kaplan, 2000). Thus, both cultural and natural tendencies need to be explored in tendon, and translated into the types of educational programs, and information programs which appeal to both innate needs (e.g. the need of secure and healthy environment) and learned culture. If this learned culture (e.g. the seeing economic growth as progressive and desired) counteracts the natural need for safe environment, this cognitive dissonance needs to be made explicit in policy and education.

\subsection{Human nature and sustainability: practical implications}

While the call for multiple sustainabilities is heard (Moncebo, 2013), as it is argued that sustainability discourse is mired in the intricacies of uncertainty, interpretation, and endless contestation, it is easy to see why cultural explanations for both causes and solutions to sustainability challenges abound. Yet, the hard reality of limited natural resources, climate change, and biodiversity loss call for recognition of a less relativistic and more instrumental approach to sustainability, which is more likely to lead to a transformative change than multiple open perspectives (Corner, 2014). Transformative change involves learning from nature's designs by developing a model of production that recognizes the integrity of the entire ecosystem as a starting point of human manufacturing (Lieder and Rashid, 2016). As reported in this journal, the approach of sufficiency, which follows the premise that we should limit what is produced or consumed in absolute terms, was proposed to avoid the rebound effect (Figge et al., 2014). Sufficiency refers to products that are not overproduced or wasted but kept in the productive loop.

In Cradle to Cradle: Remaking the Way We Make Things, McDonough and Braungart (2002) criticize the current method of production as a linear (take, make, waste) process. The conventional reduction of damage through eco-efficient use of resources serves as examples of misguided (although well-intentioned) 
methods. As the authors of Cradle to Cradle (C2C) reflected, a bad thing should not be 'efficient' but eliminated altogether. Recycling leads to 'down-cycling' resulting in energy and resource loss. Similarly to $\mathrm{C} 2 \mathrm{C}$, the idea of circular economy that draws on the understanding and appreciation of the natural systems (Ellen MacArthur Foundation) sees sustainability in terms of transition to a circular (waste equals food) model.

The C2C framework rests on a number of theoretical developments in the field of industrial ecology and ecological economics, including those developed by physicist Robert Ayres and economist Allen Kneese (1969); and engineers Frosch and Gallopoulos, 1989. Based on the laws of thermodynamics, Nicolas Georgescu-Roegen (1971), one of the founding fathers of the subdiscipline of ecological economics, argued that unlimited economic growth is physically impossible. In regard to human nature, Georgescu-Roegen (1971) has noted that the rate of evolutionary change of endosomatic organs (literally, within skin organs such as heart and kidneys) is exceedingly slow; while the rate of change of exosomatic organs (literally, outside skin types of natural and manmade capital, such as farms, and factories) has become very rapid. In fact, as noted by Daly (2016), the collective evolution of the human species is now overwhelmingly centered on exosomatic organs, such as the use of airplanes, rather than wings. This exosomatic evolution is goal-directed towards "economic growth," and that growth has been achieved largely by the depletion of nonrenewable resources (Daly, 2016). In this context, C2C framework builds on the critique of industrial system as well as techno-social adaptation that has significant side-effects in the form of ecological costs. C2C industrial design tool identifies three key design principles that address long term sustainability: (a) waste equals food; (b) use current solar income, and (c) celebrate diversity. In short, these principles are:

Waste equals food. Unproductive waste does not exist in nature because the living processes of each organism contribute to the whole ecosystem. A fruit tree's blossoms serve as food for other living things or decompose in soil. As nutrients flow indefinitely in cycles of birth, decay and rebirth, all products can be designed as nutrients that flow through natural or designed metabolisms. This designed metabolism mirrors natural cycles in a closed-loop system in which valuable, high-tech synthetics circulate in cycles of production, use, recovery and remanufacture.

Use current solar income. Trees and plants manufacture food from sunlight, an elegant, effective system that uses the earth's continuous source of energy income. Despite recent precedent, human energy systems can be nearly as effective. C2C system$s$-from buildings to manufacturing processes-tap into current solar income by using direct solar energy collection or passive solar processes, such as day-lighting, which makes effective use of natural light. Wind or tidal wave power can also be tapped.

Celebrate diversity. Diversity in natural and cultural systems need to be respected. Healthy ecosystems and traditional cultures are complex communities, each of which has developed a unique response to its surroundings that works in concert with other organisms to sustain the system. Indeed, "Ecosystem goods (such as food) and services (such as waste assimilation) represent the benefits human populations derive, directly or indirectly, from ecosystem functions" (Costanza, 1992:253). As biomimicry (Benyus, 1997), C2C takes nature's diversity as a prototype for human designs tailoring designs to maximize their positive effects and enhance the local landscape. This idea is similar to natural adaptations of humanity (and other species) to their environment and thus in this sense largely consistent with human nature.

In regard to human nature we can note that the linear production model is not 'hard-wired' as it is unprecedented in human history, but an obvious example of unintended consequences of industrial revolution (McDonough and Braungart, 2002). Also, as the current attempts and failures at mitigating environmental damage are learned and not 'inherited' some misguided efforts at fostering sustainability can be substituted by more informed practices. C2C designs, in a business sense, can offer significant financial benefits as no new costly raw materials will be required (Blowfield, 2013; Kopnina and Blewitt, 2014). The cultural or learned aspect of operating such an ecologically benign system of production can enhance the natural human propensity for technological innovation. This requires learning how C2C is different from conventional sustainability models, and how it can be applied on a global scale. An introduction of any of the hopeful frameworks on the global scale requires caution to in order to overcome natural expansionist tendencies. As Georgescu-Roegen (1971) has pointed out, even a circular system would inevitably lose energy and resources given the thrust of modern economies towards constant growth and innovation. The risk of subversion of production to the cult of ever-growing economic systems needs to be seriously addressed (Engelman, 2013; Kopnina, 2016) in terms of countering natural tendency for expansion (Rees, 2010).

There are trade-offs that need to be considered when it comes to implementing circularity ideas. Circular frameworks can be subverted to the cause of continuing business-as-usual. The companies that get on the 'best practice' examples of MacArthur Foundation still focus on minimising damage, recycling and eco-efficiency. For example, Coca Cola touts its efficiency (should be effectiveness) in recycling (should be infinitely reusing) of plastic (should be another non-damaging material) bottles. Often, circular economy is advertised as a 'new engine of growth', rather than promoting fundamental change (Kopnina, 2016). Some of the companies improve one small part of their operation, without the needed overhaul of the entire supply chain, mode of operation and the radical change in product materials. Thus, optimistic 'simple and easy' approaches need to be treated with caution (Kopnina, 2016; Lieder and Rashid, 2016).

Despite these difficulties, it is important not to 'throw the baby out with the bathwater'. While it still has a long way to go in practice, the $\mathrm{C} 2 \mathrm{C}$ and circular economy frameworks have the potential to reach beyond mainstream sustainability strategies (Kopnina, 2016). Good historical examples of ecologically benign products can be easily found in the form of pre-industrial production systems, from small-scale horticulture to clay pots. This does not mean that consumers should revert to pre-industrial lifestyle or that producers should be at a disadvantage selling products from 'retrogressive' design (Kopnina and Blewitt, 2014). Considering the challenges of creating economies of scale, innovative designs, such as hyperloop for modern transportation system (Matthews and Brueggemann, 2015), might be better adopted to the world of billion consumers than pre-industrial small-scale produced products. Typically, such innovations are supported by competitive behavior - which might well be part of human nature.

\subsection{Reflecting on positive example}

Practically, the application of $\mathrm{C} 2 \mathrm{C}$ and circular economy theory bears upon the way engineers and designers construct products, policy makers support radical re-orientation of industrial system, and ecologists instruct designers, engineers and policy makers of the optimal ecologically benign products. An example of Climatex suggests how such products can be made. The aforementioned fields of industrial ecology and ecological economics have inspired development of "green fabric". The partnership between Designtex, McDonough, Braungart and Rohner has incorporated the "waste $=$ food" principle in the brand Climatex, resulting in the fully biodegradable quality fabric which was awarded Gold-level 
C2C Certification. Remarkably for normally protective profitoriented business models, Climatex stresses the importance of transparency of its production and in fact encourages others to imitate its innovation to contribute to the economies of scale (IEHN). This potentially can make the fabric not just widely available but also affordable for various individuals involved in interior design, healthcare, automotive, transportation, clothing, shoes and other industries.

This example suggests how the 'positive' (in terms of ecological integrity) natural propensity for innovation and sharing can be applied. One of Brown's (1999) universals is cooperation between individuals - but also within and across industries, can help facilitate transition toward sustainability. As noted by Witjes and Lozano (2016), cooperation includes better access to markets and knowledge, enriched creativity, avoidance of confrontation, a decrease in the time needed to accomplish objectives. Indeed, cooperation between companies can increase trans-disciplinary learning (Fadeeva, 2004) and enable economies when different actors of green supply chain cooperate with each other. Simultaneously, a degree of competition (Matthews and Brueggemann, 2015), perhaps equally embedded in human nature as cooperation, is likely to lead to successive inventions and innovations.

Thus, returning to the question of whether both self-interest and altruism can be balanced in such a way that sustainable choices become 'natural', C2C framework does offer substantial hope that it can be done. $\mathrm{C} 2 \mathrm{C}$ framework does not force people to be unnaturally burdened by constant guilt of having a negative environmental impact, and in a cultural sense is conditional on educational and policy initiatives, as well as on revision of current methods of manufacturing and services, in which some cultural conventions need to be unlearned.

Rees (2010) outlines his working hypothesis that because of certain evolutionary traits, modern people are biased against sustainability. Yet, the genetic predispositions alone do not lead to unsustainability - it is a combination with other external factors that act together with the predisposition to make addressing sustainability very difficult. Thus, unsustainability is due to both historically specific characteristics of industrial capitalism as well as certain features of human nature (Kaplan, 2000; Kopnina, 2013a). Rees (2010:15) states, "humanity's technological prowess and society's addiction to continuous material growth reinforce the biological drivers, making the problem particularly intractable. More specifically, I hypothesize that unsustainability is an inevitable emergent property of the systemic interaction between contemporary technoindustrial society and the ecosphere. Both genetic and socio-cultural factors contribute to the conundrum".

Thus, a tendency for expansion is reinforced by the socially constructed economic narrative of continuous material growth, perpetuated by industrially developed neoliberal societies, resulting in cognitive dissonance and collective denial (Washington, 2015).

An example of what types of cultural practices can be unlearned is the odd aesthetics of urban planning. As McDonough and Braungart (2002) note, in present urban designs 'diversity - an integral part of natural world - is treated as a hostile force (p.32). They reflect: 'The average lawn is an interesting beast: people plant it, then douse it with artificial fertilizers and dangerous pesticides to make it grow and keep it uniform - all so that they can hack and mow what they encouraged to grow. And woe to the small yellow flower that raises its head!' (Ibid, p. 33). Indeed, the use of energy, water, pesticides and insecticides that are involved in keeping 'neat' lawns, even in natural desert environments, basically serves to destroy any biodiversity and pollutes the environment (Kopnina, 2013b, 2015b). The easy solution for saving labor and electricity costs involved in mowing and watering the lawns can be easily accomplished by simply not exercising this odd cultural practice which eliminates biodiversity in urban spaces. There is nothing unnatural about that.

\section{Conclusion}

It was argued that understanding of both altruistic and profitmaximizing tendencies (which often coincide with self-regarding/ self-interested motivation) allows us to see why certain measures targeted at enhancing sustainable action are ineffective, while others are easier to implement as they are congruent with natural tendencies. This article focused on the differences between 'natural' (hard-wired and hardly changeable) features of human behavioral repertoire and those cultural, social, and generally 'conditioned' or 'learned' features that can be easily influenced and changed. Future interdisciplinary research that includes both psychological experiments (by, for example, social psychologists and consumer behavior specialists), cross-cultural observations (by, for example, anthropologists) and behavioral theories (by, for example, biologists) could add insight to the types of situations and actions that 'naturally' foster sustainability. This article has laid an accent on behaviors that can support transformative sustainability frameworks, such as C2C and circular economy. Some education specialists already place great accent on learned behaviors that support these transformative frameworks, by, firstly, teaching about the difference between conventional (eco-efficiency, recycling) models and more radical (complete elimination of unproductive waste) models, and providing theoretical and practical examples, as to how sustainability can be achieved (e.g. Kollmuss and Agyeman, 2002; Chawla and Cushing, 2007; Kopnina, 2012; Kirner, 2017).

Population growth, in combination with human natural propensity to expand (Rees, 2010), can be best addressed through both self-interest and altruism. Caring about future generations implies the necessity of non-coercive measures addressing population growth. Human nature does not dictate how many children one should have. Also, human nature does not dictate what type of production system should be employed, but the capacity for innovation can serve the cause of switching from the damaging industrial cradle-to-grave production to a more ecologically intelligent designs.

While self-interest may be one of the more powerful forces in human behavior, in the context of sustainability it can be used for collective good, as in the case of competition that stimulates innovative designs. As Fehr-Duda and Fehr (2016) have noted, care for others and cooperation is also part of our nature, which in the case of sharing of ideas can help ecologically benevolent designs to take precedence.

Generally, many examples in human history, including social justice and equality movements, demonstrate that it is possible to mobilize the better angels of our nature (Pinker, 2011) to improve the human condition (Fehr-Duda and Fehr, 2016). Ideally, care for the environment and our own self-interest as species dependent on this environment, will lead to radical re-orientation of the system of production towards more ecologically benign C2C and circular economy models. If the wonderful capacity for empathy can be expanded to nonhuman species - and there is plenty of evidence that cross-culturally and historically, it already is (Wilson, 1984; Kopnina, 2015a, 2015b; Sponsel, 2016) - we may yet live in a truly sustainable world. Less idealistically, pragmatic considerations call for the assessment of financial feasibility of re-orienting the entire chain of production towards ecologically benign models, as well as removing a number of structural factors. 


\section{References}

Ayres, R.U., Kneese, A.V., 1969. Production, consumption, and externalities. Am. Econ. Rev. 59, 282-297.

Ayres, R.U., van den Bergh, J.C.J.M., Lindenberger, D., Warr, B., 2013. The underestimated contribution of energy to economic growth. Struct. Change Econ. Dyn. 27, 79-88.

Banda, M., 2015. Memory Banda: a Warrior's Cry against Child Marriage. Ted Talk. https://www.ted.com/talks/memory_banda_a_warrior_s_cry_against_child_ marriage.

Benyus, J.M., 1997. Biomimicry: Innovation Inspired by Nature. Harper Collins Publishers, New York.

Blowfield, M., 2013. Business and Sustainability. Oxford University Press, Oxford.

Bocken, N.M.P., Short, S.W., Rana, P., Evans, S., 2014. A literature and practice review to develop sustainable business model archetypes. J. Clean. Prod. 65, 42-56.

Brown, D.E., 1991. Human Universals. McGraw-Hill, New York.

Campbell, M., 2012. Why the silence on population? In: Cafaro, P., Crist, E. (Eds.), Life on the Brink: Environmentalists Confront Overpopulation. University of Georgia Press, Atlanta, pp. 41-56.

Chawla, L., Cushing, D., 2007. Education for strategic environmental behaviour. Environ. Educ. Res. 13 (4), 437-452.

Corner, A., 2014. The Communication of Uncertainty Is Hindering Climate Change Action. The Guardian. January 31. http://www.theguardian.com/sustainablebusiness/climate-change-communication-uncertainty.

Costanza, R., 1992. Ecosystem Health: New Goals for Environmental Management. Island Press, Washington, DC.

Crist, E., 2012. Abundant earth and the population question. In: Cafaro, P., Crist, E. (Eds.), Life on the Brink: Environmentalists Confront Overpopulation. University of Georgia Press, Atlanta, pp. 141-153.

Daly, H.E., 2016. In: Washington, H., Twomey, P. (Eds.), A Population Perspective on the Steady State Economy. A Future beyond Growth: towards a Steady State Economy. Routledge, New York, pp. 17-29.

Deemer, D., 2015. Poor Chicken: Why Poor People Care More about Animal Welfare than Wealthy Shoppers. https://thebluereview.org/why-poor-people-caremore-about-animal-welfare-than-wealthy-shoppers/.

Dunlap, R.E., Van Liere, K.D., 1978. The new environmental paradigm: a proposed measuring instrument and preliminary results. J. Environ. Educ. 9 (4), 10-19.

Ehrenfeld, D., 1978. The Arrogance of Humanism. Oxford University Press, New York.

Engelman, R., 2013. Beyond sustainababble. In: Starke, L. (Ed.), State of the World 2013: Is Sustainability Still Possible? Island Press, Washington.

Fadeeva, Z., 2004. Promise of sustainability collaboration-potential fulfilled? J. Clean. Prod. 13, 165-174.

Fehr-Duda, H., Fehr, E., 2016. Sustainability: game human nature. Nature 530, 413-415.

Figge, F., Young, W., Barkemeyer, R., 2014. Sufficiency or efficiency to achieve lower resource consumption and emissions? The role of the rebound effect. J. Clean. Prod. 69, 216-224.

Fletcher, R., Breitlin, J., Puleo, V., 2014. Barbarian hordes: the overpopulation scapegoat in international development discourse. Third World Q. 35 (7), 1195-1215.

Frosch, R.A., Gallopoulos, N.E., 1989. Strategies for manufacturing. Sci. Am. 261, $144-152$.

Fukuyama, F., 1999. The Great Disruption: Human Nature and the Reconstitution of Social Order. Free Press, New York.

Georgescu-Roegen, N., 1971. The Entropy Law and the Economic Process, Cambridge, MA. Harvard University Press.

Gifford, R., 2011. The dragons of inaction: psychological barriers that limit climate change mitigation and adaptation. Am. Psychol. 66 (4), 290.

Goklany, I.M., 2007. The Improving State of the World: Why We're Living Longer; Healthier, More Comfortable Lives on a Cleaner Planet. Cato Institute.

Hansen, A., Wethal, U., 2014. Emerging Economies and Challenges to Sustainability: Theories, Strategies, Local Realities. Routledge, New York.

Hindin, M.J., Kalamar, A.M., Thompson, T.A., Upadhyay, U.D., 2016. Interventions to prevent unintended and repeat pregnancy among young people in low-and middle-income countries: a systematic review of the published and gray literature. J. Adolesc. Health 59 (3), S8-S15.

IEHN. Rohner textiles: cradle-to-cradle innovation and sustainability.http://www. iehn.org/publications.case.rohner.php.

Ingold, T., 2006. In: Gontier, N., Bendegem, J.P., Aerts, D. (Eds.), Against Human Nature. Evolutionary Epistemology, Language and Culture. Springer, Dordrecht, Netherlands, pp. 259-281.

Isenhour, C., 2015a. In: Kopnina, H., Shoreman-Ouimet, E. (Eds.), Sustainable Consumption and its Discontents. Sustainability: Key Issues. Routledge, New York, pp. 133-154.

Isenhour, C., 2015b. Sustainable consumption and its discontents. In: Kopnina, H., Shoreman-Ouimet, E. (Eds.), Sustainability: Key Issues. Routledge, New York, pp. $133-155$.

Kaplan, S., 2000. Human nature and environmentally responsible behavior. J. Soc. Issues 56 (3), 491-508.

Kellert, S.R., Wilson, E.O., 1995. The Biophilia Hypothesis. Island Press, Washington, London.

Kidner, D., 2014. Why "anthropocentrism" is not anthropocentric. Dialect. Anthropol. $38,465-480$.
Kirner, K., 2017. Cognition and cultural modeling. In: Kopnina, H., ShoremanOuimet, E. (Eds.), Routledge Handbook of Environmental Anthropology. Routledge, Abingdon and New York, pp. 428-440.

Kollmuss, A., Agyeman, J., 2002. Mind the gap: why do people act environmentally and what are the barriers to pro-environmental behavior? Environ. Educ. Res. 8 239-260.

Konner, M., 2003. The Tangled Wing: Biological Constraints on the Human Spirit. Holt Paperbacks, Chicago.

Kopnina, H., 2012. Education for Sustainable Development (ESD): the turn away from 'environment' in environmental education? Environ. Educ. Res. 18 (5), 699-717.

Kopnina, H., 2013a. The grand old theory of human nature and environmental problems. J. Ecol. Anthropol. 16 (1), 61-68.

Kopnina, H., 2013b. Requiem for the weeds: reflections in Amsterdam city park. Sustain. Cities Soc. 9, 10-14.

Kopnina, H., 2015a. Revisiting the Lorax complex: deep ecology and biophilia in cross-cultural perspective. Environ. Sociol. 43 (4), 315-324.

Kopnina, H., 2015b. Requiem for the urban weeds: an exploration of green spaces in Amsterdam. Urban Ecosyst. 18 (4), 1125-1137.

Kopnina, H., 2016. Closed loop production models in Environmental Education: teaching circular economy and the business of subversion. In: Washington, H. Twomey, P. (Eds.), A Future beyond Growth: towards a Steady State Economy Routledge, New York.

Kopnina, H., Blewitt, J., 2014. Sustainable Business: Key Issues. Routledge, London.

Kopnina, H., Gjerris, M., 2015. Are some animals more equal than others? Animal Rights and Deep Ecology in environmental education. Can. J. Environ. Educ. 20, 109-123.

Kopnina, H., Washington, H., 2016. Discussing why population growth is still ignored or denied. Chin. J. Popul. Resour. Environ. 14 (2), 133-143.

Lewis, C.A., 1996. Green Nature/Human Nature: the Meaning of Plants in Our Lives. University of Illinois Press, Urbana, IL.

Lieder, M., Rashid, A., 2016. Towards circular economy implementation: a comprehensive review in context of manufacturing industry. J. Clean. Prod. 115 36-51.

Matthews, C.H., Brueggemann, R., 2015. Innovation and Entrepreneurship: a Competency Framework. Routledge, New York.

McDonough, W., Braungart, M., 2002. Cradle to Cradle: Remaking the Way We Make Things. Vintage Books, London.

Miller, D., 2001. The poverty of morality. J. Consumer Cult. 1 (2), 225-244.

Moncebo, F., 2013. The pitfalls of sustainability policies: insights into plural sustainabilities. Challenges Sustain. 1 (1), 29-40.

Nemetz, P.N., 2015. Reconstructing the sustainability narrative. In: Kopnina, H., Shoreman-Ouimet, E. (Eds.), Sustainability: Key Issues. Routledge, New York, pp. 38-49.

Noss, R.F., 1992. The wildlands project land conservation strategy. Wild Earth (1), 9-25.

Panksepp, J., 1998. Affective Neuroscience: the Foundations of Human and Animal Emotions. Oxford University Press, Oxford.

Pinker, S., 2011. The Better Angels of Our Nature: Why Violence Has Declined. Penguin.

Polasky, S., Johnson, K., Keeler, B., Kovacs, K., Nelson, E., Pennington, D. Plantinga, A.J., Withey, J., 2012. Are investments to promote biodiversity conservation and ecosystem services aligned? Oxf. Rev. Econ. Policy 28 (1), 139-163.

Ratzel, F., 1896. In: Butler, A.J., M. A (Eds.), The History of Mankind Translated from the Second German. E. B. Tylor. Macmillan, London with introduction by.

Rees, W., 2010. What's blocking sustainability? Human nature, cognition, and denial. Sustain. Sci. Pract. Policy 6 (2), 13-25.

Schwartz, S.H., 1994. Are there universal aspects in the structure and contents of human values? J. Soc. Issues 50 (4), 19-46.

Shoreman-Ouimet, E., Kopnina, H., 2016. Culture and Conservation: beyond Anthropocentrism. Routledge, New York.

Simon, J., 1981. The Ultimate Resource. Princeton University Press, Princeton.

Singh, S., Sedgh, G., Hussain, R., 2010. Unintended pregnancy: worldwide levels, trends, and outcomes. Stud. Fam. Plan. 41 (4), 241-250.

Sivek, D., 2002. Environmental sensitivity among Wisconsin high school students Environ. Educ. Res. 8 (2), 155-170.

Spannring, R., 2016. Animals in environmental education research. Environ. Educ Res. http://dx.doi.org/10.1080/13504622.2016.1188058.

Sponsel, L., 2016. Spiritual ecology, sacred places, and biodiversity conservation. In: Kopnina, H., Shoreman-Ouimet, E. (Eds.), Routledge Handbook of Environmental Anthropology. Routledge, New York, pp. 132-144.

Taylor, B., 2010. Dark Green Religion: Nature Spirituality and the Planetary Future. University of California Press, Berkeley.

The Economist, 2012a. America's Demographic Squeeze: Double Bind. http://www. economist.com/news/united-states/21568398-falling-birth-rate-and-muchslower-immigration-presage-long-term-trouble-ahead-double.

The Economist, 2012b. Demography: Virility Symbols, p. 34. http://www.economist com/node/21560266. August 11.

The Economist, 2015a. Groupthink. http:/www.economist.com/news/specialreport/21678952-peoples-views-climate-change-go-hand-hand-their-politicsgroupthink.

The Economist, 2015b. Climate Change: Hot and Bothered. http://www.economist com/news/special-report/21678951-not-much-has-come-efforts-preventclimate-change-so-far-mankind-will-have-get. 
United Nations, 2015. Transforming Our World: the 2030 Agenda for Sustainable Development. transformingourworld.

Veblin, T., 1902. The Theory of the Leisure Class: an Economic Study of Institution. Macmillan, New York.

Vucetich, J.A., Nelson, M.P., 2013. The infirm ethical foundations of conservation. In: Beckoff, M. (Ed.), Ignoring Nature No More: the Case for Compassionate Conservation. University of Chicago Press, Chicago, pp. 9-25.

Washington, H., 2015. Demystifying Sustainability: towards Real Solutions. Routledge, London.

WHO (World Health Organization), 2016. Family Planning/Contraception. http:// who.int/mediacentre/factsheets/fs351/en/.

Wijkman, A., Rockström, J., 2012. Bankrupting Nature: Denying Our Planetary Boundaries. Routledge, New York.

Wilk, R., 2011. In: Ekström, K.M., Glans, K. (Eds.), Consumption in an Age of Globalization and Localization. Beyond the Consumption Bubble. Routledge, New York, pp. 37-51.

Wilson, E.O., 1984. Biophilia: the Human Bond with Other Species. Harvard University Press, Cambridge.
Wilson, E.O., 1993. Biophilia and the conservation ethic. In: Kellert, S.R., Wilson, E.O. (Eds.), The Biophilia Hypothesis. Island Press, Washington, DC, pp. 31-41, 1993. Witjes, S., Lozano, R., 2016. Towards a more Circular Economy: proposing a framework linking sustainable public procurement and sustainable business models. Resour. Conserv. Recycl. 112, 37-44.

Dr. Kopnina, Helen (Ph.D. Cambridge University, 2002) is a researcher in the fields of environmental education and environmental social sciences. Helen is currently employed at both at the Leiden University and at The Hague University of Applied Science (HHS) in The Netherlands. At the Leiden Institute of Cultural Anthropology and Development Sociology she is an Assistant Professor of environmental anthropology. At the HHS, she is a coordinator and lecturer of Sustainable Business program. Helen is the author of over seventy peer reviewed articles and (co)author and (co)editor of twelve books, including Sustainability: Key Issues (2015); Culture and Conservation: Beyond Anthropocentrism (2015); and Handbook of Environmental Anthropology (2016). 